\title{
Surface Quality of Jute Fibre Reinforced Polyester Composite by Abrasive Waterjet Machining
}

\author{
Kalirasu S., Rajini N., Rajesh S., Gopikumar S., Arunkumar K., Mukesh Vaidya C. M.
}

\begin{abstract}
Unpleasantness in the job assumes an essential job in distinguishing manner that is how the genuine item cooperates with the encompassing world in the field of engineering. The Harsh surface gets wear easily and quickly, so consequently, the article producing area needs to get a mass in it. Nowadays composite assumes a vital job due to some great properties. Along these lines, composite needs to get more focus in its new trend. In cutting innovation, the instrument wear is the most important factor that should be considered. There is some non-customary machining process in which the cutting instrument isn't utilized in it. In this technique we utilize Abrasive water jet machine (AWJM) since it is a standout most utilized non-customary machining process, which has no cutting tools and the blend of rough molecule of garnet 80 mesh and high-pressure water from the spout is utilized to cut the workpiece with some of the parameters like grating stream rate, remain off separation, feed rate and siphon weight. The jute fiber reinforced unsaturated polyester composite (JF/UPR) created by pressure forming which is utilized for estimating surface Roughness (Ra) and furthermore to locate the base surface unpleasantness by changing the three distinct parameters of pressure $(P)$, Standard of distance $\left(S_{d}\right)$ and feed rate $\left(V_{f}\right)$ with the predetermined evaluation of grating molecule.
\end{abstract}

Keywords: Composite, AWJM, Surface roughness.

\section{INTRODUCTION}

Water jet machining, a high-velocity water jet is passed to strike a workpiece. During this process, high-pressure energy is converted to kinetic energy. Later on, abrasives are added. This high-pressure water jet is used for cutting high strength and hard materials. The water jet process provides many unique capacities and advantages to reduce cost. Water jet technology is the fastest growing technology in the world. Toxic fumes, recast layers, slag, and thermal stress are totally eliminated. Cutting forces are less and no heat affecting zone near the cutting area [1-3]. [4] It has been reported that the layered composites are difficult to machine as it is heterogeneous due to the matrix properties, fiber orientation and relative volume fraction of matrix.

Revised Manuscript Received on December 29, 2019.

S. Kalirasu*, Associate Professor, Department of Mechanical Engineering, Kalasalingam Academy of Research and Education, Krishnankoil-626126, Tamilnadu, India. Email: kalirasu.s@gmail.com.

N. Rajini, Professor, Department of Mechanical Engineering, Kalasalingam Academy of Research and Education, Krishnankoil-626126, Tamilnadu, India. Email: rajiniklu@gmail.com

S. Rajesh, Associate Professor, Department of Mechanical Engineering, Kalasalingam Academy of Research and Education, Krishnankoil-626126, Tamilnadu, India. Email: s.rajesh@klu.ac.in

S. Gopikumar, UG Students, Department of Mechanical Engineering, Kalasalingam Academy of Research and Education, Krishnankoil-626126, Tamilnadu, India.

K. Arunkumar, UG Students, Department of Mechanical Engineering, Kalasalingam Academy of Research and Education, Krishnankoil-626126, Tamilnadu, India.

G. M. Mukesh vaidya, UG Students, Department of Mechanical Engineering, Kalasalingam Academy of Research and Education, Krishnankoil-626126, Tamilnadu, India.
AWJM has proven to be a viable technique to machine such materials compared to conventional machining. [5] Comparative study of unidirectional graphite/epoxy composite material has been machined by water jet and AWJM processes. Based on previous studies AWJ machining is found to be a more feasible machining process for unidirectional graphite/epoxy due to its material removal mechanisms, and superior quality surface generation. [6] It is also an effective technology for processing metallic coated sheet steels with good key quality and commercially acceptable productivity. $[7,8]$ The cutting stroke in AWJM is influenced by the grain size of the abrasive powder. [9] Even though with the help of water the cutting of material can be done but for harder materials, the abrasives should be added. [10] The pressure of water depends upon the area of the nozzle that is used. [11] There is the various size of abrasive grain size is available. As per the factors the size of grain size can be selected. [12] The quality of machining is determined by the surface finish of the materials. [13] The average surface thickness of $6 \mathrm{~mm}$ can be machined using AWJM. [14] The velocity and pressure of the water is the important factor that is considered in the AWJM. [15] Abrasive used, Grain size of the abrasives are some other factors that should be considered for AWJM.

\section{EXPERIMENTAL DETAILS}

\section{A. Materials used}

Jute fibers are used for the fabrication of plate. To reinforce the fiber, polyester resin is applied which has a density of 1.9 to $2.0 \mathrm{~kg} / \mathrm{dm}^{3}$. These were supplied by vasavibala resins (P) Ltd, Chennai.

\section{B. Preparation of composite}

The jute fiber is cut into the shape of the mould in size of $30 \times 13 \mathrm{~cm}$ and then polished wax is applied over the moulds to remove the plate after fabrication with ease and then the required amount of polyester resin is taken. The jute fiber of $163 \mathrm{~g}$ is placed in the mould cavity and the polyester resin is gradually spread over the jute fiber and it is covered by upper mould. And it is subjected to compression moulding about to a pressure of $120 \mathrm{psi}$ and it takes around 4 hours for curing time. After curing of fiber it is been removed off from the compression moulding the excess resins and fibers are been trimmed off. And the plate that we required for the testing has been obtained at the weight of $555 \mathrm{~g}$. The percentage of jute fiber is calculated by dividing the weight of fiber by composite weight we obtain $30 \%$. Now, this can be used for the next process. 


\section{MACHINING AND MEASUREMENTS}

\section{A. Cutting of plate through AWJM}

Figure 1. Shows the AWJM nozzle setup with abrasive feeder. The manufactured jute fiber plate is set on the work table of AWJM machine with the accessibility of determined garnet 80 mesh grating particles with a blend of water for cutting the plate according to the given contribution of pressure, feed rate, stand-off distance. The plate has been cut into 54 bits of $2 \mathrm{~cm}$ to quantify the surface unpleasantness of the plate by shifting the above parameters.

\section{B. Measurement of Surface Roughness}

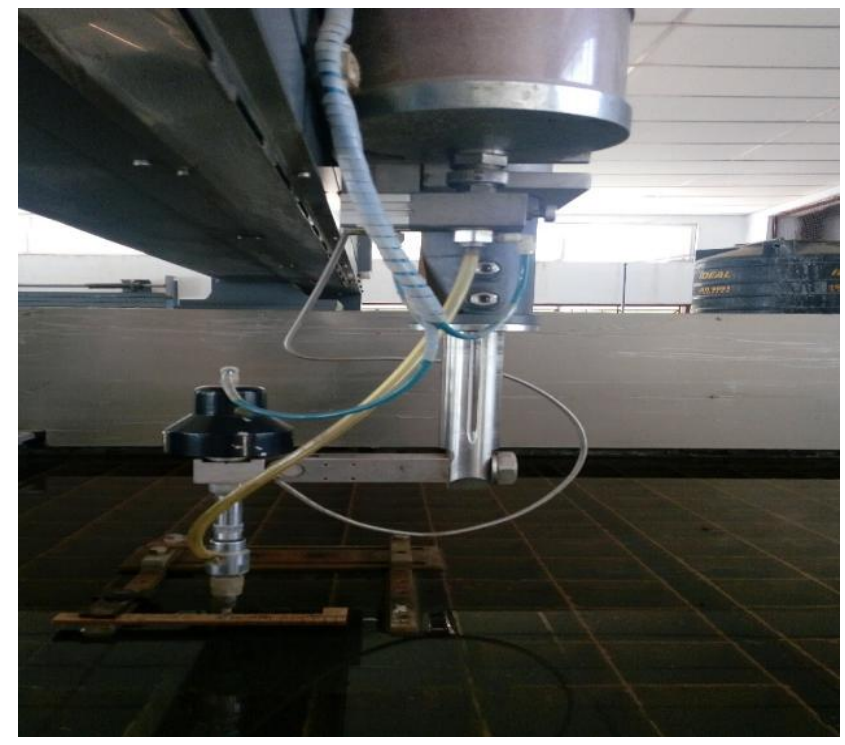

Fig. 1. Abrasive Water Jet Machine

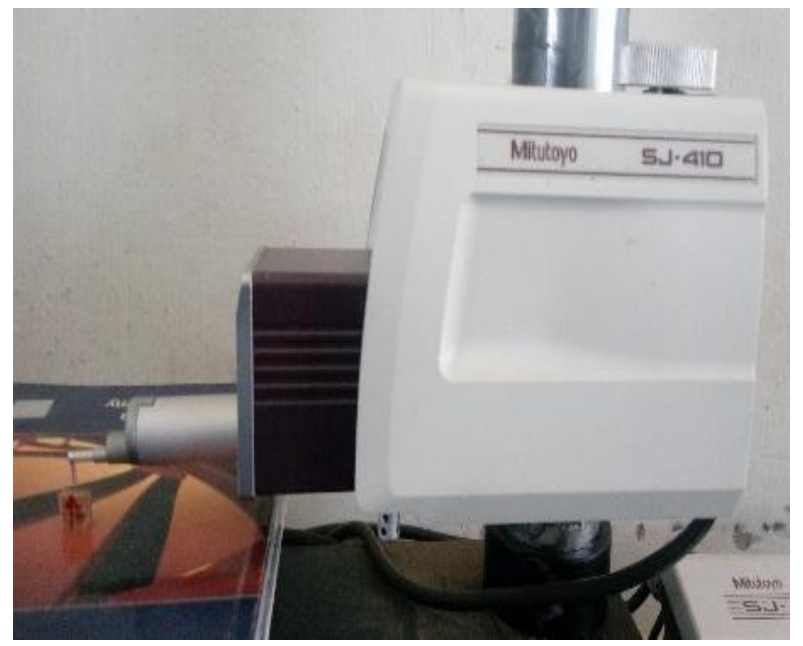

Fig. 2. Surface Roughness Testing Machine

Figure 2. Shows the surface roughness testing machine. The surface roughness of the created JF/UPR composite is dictated by surface roughness testing machine. Spot the estimating test legitimately and look at it with no blunder. Place the workpiece on the table and now modify the agent to contact tip of the fiber up to the sign of the green light and furthermore give contribution of length of material for recognizable proof reason for the machine is up to $20 \mathrm{~mm}$ and now begin the machine and now the test moves from the one end to opposite end and holds to the beginning stage. Now the readings are shown in the screen according to this following the rest of the readings are been noted lastly the 54 distinct qualities are been framed as table configuration for simple distinguishing proof of the estimating of least surface harshness of the predefined grating molecule on these composite materials.

Table - I: Parameters and Levels

\begin{tabular}{|c|c|c|c|c|}
\hline \multirow[t]{2}{*}{ S.No } & \multirow[t]{2}{*}{ Parameters } & \multicolumn{3}{|c|}{ Levels } \\
\hline & & 1 & 2 & 3 \\
\hline 1. & P (Mpa) & 150 & 200 & 250 \\
\hline 2 & $\mathrm{~S}_{\mathrm{d}}(\mathrm{mm})$ & 1 & 2 & 3 \\
\hline 3 & $\mathrm{~V}_{\mathrm{f}}(\mathrm{mm} / \mathrm{s})$ & 20 & 30 & 40 \\
\hline
\end{tabular}

Table - II: Surface Roughness Readings

\begin{tabular}{|c|c|c|c|}
\hline $\mathbf{P}(\mathbf{M p a})$ & Sd (mm) & $\mathbf{V f}(\mathbf{m m} / \mathbf{s})$ & $\mathbf{R a}(\boldsymbol{\mu m})$ \\
\hline 250 & 1 & 20 & 0.07 \\
\hline 250 & 1 & 30 & 0.12 \\
\hline 250 & 1 & 40 & 0.18 \\
\hline 250 & 1 & 20 & 0.07 \\
\hline 250 & 2 & 20 & 0.13 \\
\hline 250 & 3 & 20 & 0.18 \\
\hline 150 & 1 & 20 & 0.15 \\
\hline 200 & 1 & 20 & 0.10 \\
\hline 250 & 1 & 20 & 0.07 \\
\hline
\end{tabular}

Table I. demonstrates the information given to the machine so as to locate the Ra of JF/UPR composite, the objective to distinguish the Ra with various information parameters with the assistance of AWJM. JF/UPR composite with the elements of $30 \mathrm{~cm} \times 13 \mathrm{~cm}$ which is set in AWJM with some coordinated joints. In this manner, the plate is fixed. Finally, the pressure, $V_{f}, S_{d}$ has been referenced in the table as a consequence of information parameter dependent on the esteem, the $\mathrm{Ra}$ is acquired. Every single feed rate has diverse surface harshness, along these lines when each info parameters change as per that surface unpleasantness will get differed base on the information which was given. Table II. Demonstrates the parameters and levels which are the distinctive parameters with the diverse dimensions have been done on our task. Because of this analysis, we got three diagrams which shows the connection between the $\mathrm{Ra}$ versus three distinct parameters.

\section{RESULT AND DISCUSSION}

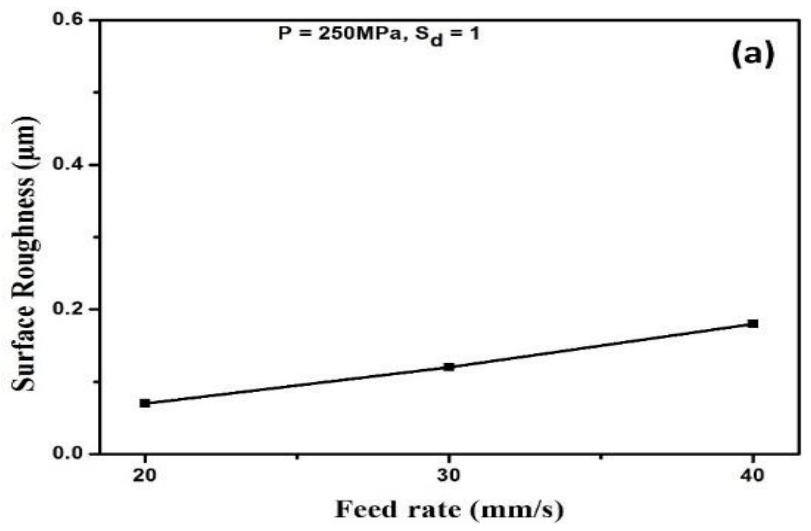

Fig.3(a). Effect of $V_{f}$ at $P=250 M P a, S_{d}=1 \mathrm{~mm}$ 


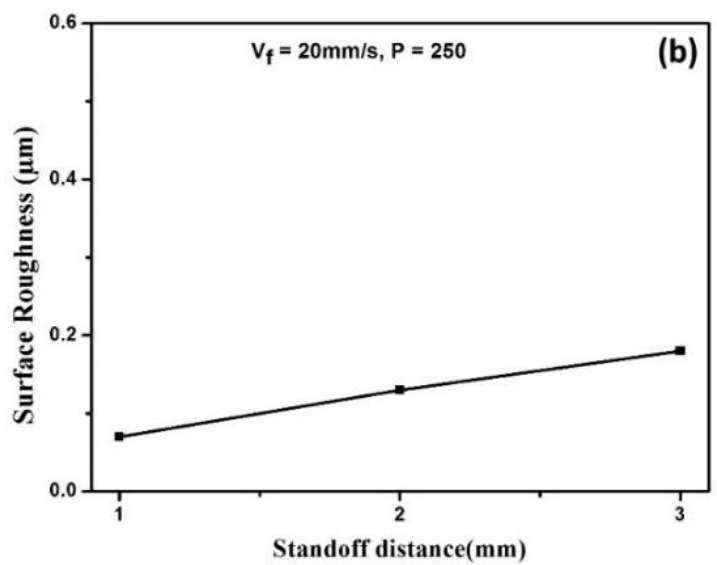

Fig.3(b). Effect of Sd at $P=250 \mathrm{MPa}, V f=20 \mathrm{~mm} / \mathrm{s}$

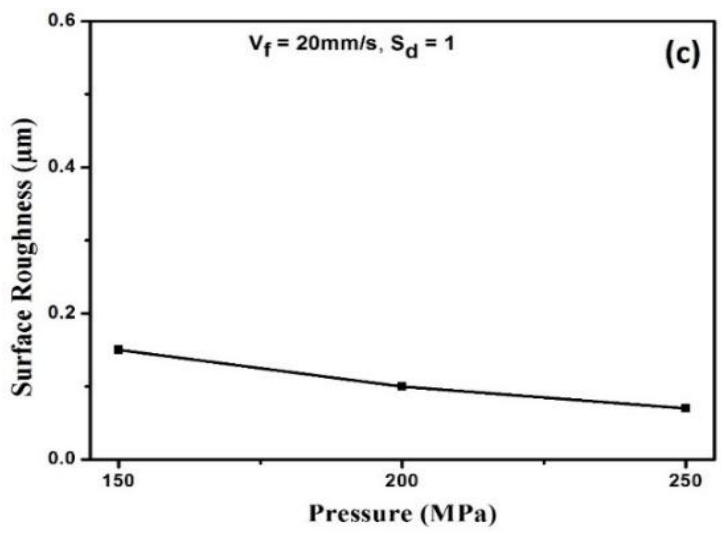

Fig.3(c). Effect of Pressure at $S d=1 \mathrm{~mm}, \mathrm{Vf}=20 \mathrm{~mm} / \mathrm{s}$

Figure 3(a) speaks to the connection between the Ra versus feed rate. This diagram demonstrates the three diverse feed rate with some particular parameters to know the surface unpleasantness. This chart has obviously demonstrated that if the feed rate builds the surface unpleasantness will get expanded, when the information parameters with the weight $250 \mathrm{MPa}, \mathrm{S}_{\mathrm{d}} 1 \mathrm{~mm}$, and the material is jute fiber strengthened with polyester resin. To accomplish the surface smoothness, the feed rate should be diminished. This implies the feed rate must be some particular however principle downside of this parameter, as feed rate decline the cutting time will get diminished. It prompts hinder the assembling procedure. It implies time utilization is high.

Figure 3(a) The Representation of the graph denotes that if the feed rate is increased the $\mathrm{Ra}$ of the material is also been increased

Figure 3(b) speaks to the connection between the Ra versus $S_{\mathrm{d}}$. This chart demonstrates the near incentive with three diverse remain off separation with some particular parameters. This diagram has obviously demonstrated that in the event that they remain off separation expands, at that point the surface harshness will get expanded, when the info parameters with the weight $250 \mathrm{MPa}$, feed rate $20 \mathrm{~mm} / \mathrm{s}$ and the material is JF/UPR composite. To accomplish the surface smoothness, remain off separation should be diminished. This implies the $S_{d}$ must be some particular however fundamental downside of this parameter, as remain off separation decline the cutting time will get diminished as same as feed rate versus surface harshness. By and by time utilization is high with the remain off separation parameter. These two-parameters results in tedious however the third parameter is unique. Weight is unique in relation to the other two parameters. With these two parameters, we can say that the rough water fly machining isn't reasonable for composite materials.

Figure 3(b) The representation of the graph denotes that if the standoff distance is increased the surface roughness of the material is also increased.

Figure 3(c) The Representation of the graph denotes that if the pressure is increased the surface roughness of the material is been reduced.

Figure 3(c) speaks to the connection between the Ra versus Pressure. This chart demonstrates the three distinct weights with some particular parameters to know the surface harshness. This diagram has unmistakably demonstrated that if the weight builds the surface harshness will get diminished when the information parameters with the feed rate $20 \mathrm{~mm} / \mathrm{s}, S_{\mathrm{d}} 1 \mathrm{~mm}$, and the material is JF/UPR composite. Surface smoothness has been accomplished. This demonstrates whatever the feed rate and $S_{d}$ the weight should be more explicit than others. Weight is the exceptional parameter, with this we can say that the composite materials can be prepared in rough water fly machining. This will build the assembling time. In this way, time utilization is less. At that point by deciding every one of the three parameters pressure $(250 \mathrm{MPa}), \mathrm{S}_{\mathrm{d}}(1 \mathrm{~mm}) \&$ feed rate $(20 \mathrm{~mm} / \mathrm{s})$ we found the base surface unpleasantness on this jute fiber.

\section{CONCLUSION}

From testing the specimen, the JF/UPR composite material we have discovered that by changing the feed rate and other parameters during machining leads to a staying steady state. We noticed an expansion in feed rate likewise expands the surface hardness of the material. At that point, by differing the $S_{d}$ and different parameters staying steady we noticed an expansion in $S_{d}$ likewise an expanding in the surface roughness of the material. At that point by shifting the weight and the other parameters stay steady and there we found the expansion in the weight and the other factors diminishes in the surface harshness. At that point by deciding every one of the three parameters pressure (250MPa), $S_{d}(1 \mathrm{~mm}) \& V_{f}(20 \mathrm{~mm} / \mathrm{s})$ we found the base surface hardness on this JF/UPR composite.

\section{REFERENCES}

1. J. Wang, "A machinability study of polymer matrix composites using abrasive waterjet cutting technology," J. Mater. Process. Technol., Vol. 94/1, 1999, pp. 30-35.

2. P. Sitarama Chakravarthy, N. Ramesh Babu, "A New Approach for Selection of Optimal Process Parameters in Abrasive Water Jet Cutting,” J. Mater. Manuf. Process., Vol. 14(4), 1999, pp. 581-600.

3. P. Sitarama Chakravarthy, N. Ramesh Babu, "A hybrid approach for selection of optimal process parameters in abrasive water jet cutting," J. Eng. Manuf., 2000, vol. 214(9), 2000, pp. 781-791.

4. D. K. Shanmugam, S. H. Masood, "An Investigation on kerfs characteristics in abrasive water jet cutting of layered composite," J. Mater. Process. Technol., vol. 209(8), pp. 3887-3893,

5. M. Ramuluet, D. L. Arola, "Water jet and abrasive water jet cutting of unidirectional polyester composite," J. Compos., vol. 24(4), pp. 299$308,1993$.

6. J. Wang, W. C. K. Wong, "A study of abrasive water jet cutting of metallic coated sheet steels", Int. J. Mach. Tool. Manu., vol.39, pp.855-870, 1999.

7. P. J. Engel, "Impact wear of materials," Chapter 4 by Finnie, Elsevier, pp. 356,1978 . 
8. Ahmet Hascalik, Ulas Caydas, Hakan Gurun, "Effect of traverse speed on abrasive waterjet machining of Ti-6Al-4V alloy", Mater. Des., Vol. 28(6), pp. 1953-1957, 2007,

9. J. G. A. Bitter, "A study of erosion phenomena Part I," Wear, Vol. 6(1), pp. 5-21, 1963,

10. J. G. A. Bitter, "A study of erosion phenomena Part II," Wear, Vol. 6(3), pp. 5169-190, 1953,

11. M. Hashish, "A model for abrasive water jet machining," J. Eng. Mater. Technol., Vol. 111, pp. 154-162, 1989.

12. J. Zeng, and T. J. Kim, "An erosion model of polycrystalline ceramic in abrasive water jet cutting," Wear, Vol. 193(2), pp. 207-217, 1996.

13. H. Hocheng, H. Y. Tasi, J. J. Shiue and B. Wang, "Feasibility study of Abrasive water jet milling of Fiber Rein forced Plastics," J. Manuf. Sci. Eng., 1997, Vol. 119, pp. 133-142, 1997.

14. D. Arola and M. Ramulu, "Material removal in abrasive waterjet machining of metals Surface integrity and Texture", Wear, 1997, Vol. 210, pp. 50-58.

15. J. Wang, "A study of abrasive waterjet cutting of metallic coated sheet steels," Int. J. Mach. Tool. Manu., 1999, Vol.39, pp. 855-870.

\section{AUTHORS PROFILE}

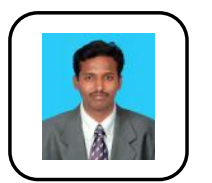

Dr. S. Kalirasu obtained his Bachelor's degree in Automobile engineering from K.L.N.College of Engineering; Madurai affiliated to Anna University, Chennai in 2009. He was awarded his Master's degree in CAD/CAM from Kalasalingam University, Krishnankoil in 2012. Then he was awarded his $\mathrm{PhD}$ in Mechanical Engineering from Kalasalingam Academy of Research and Education, Krishnankoil in 2018, He has published 10 international journals and also published more than 10 papers in International Conference proceedings. His research interest is on the fabrication of natural fiber composites and machining studies. He was an Editor for the third International Conference on Advanced Manufacturing and Automation (INCAMA) 2018. Now he is working as an Associate professor in the Department of Mechanical Engineering, Kalasalingam Academy of Research and Education since, 2012.

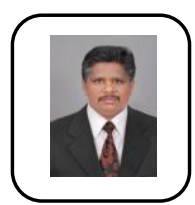

Dr. N. Rajini obtained his Bachelor's degree in Mechanical Engineering from Manonmaniam Sundaranar University, Tirunelveli in 1999. He was awarded his Master's degree in Engineering Design from Anna University, Chennai in 2004. Then he completed his PhD in Composite Materials from Kalasalingam University, Krishnankoil in 2013 and then his post-doctoral fellowship in Ghent University, Belgium in 2015. He was a visiting scientist at INTROP, Malaysia and KMUTNB, Bangkok. He is a life time member of ISTE. He brings to his position in a well-balanced background in polymers. He has published more than 70 international journals and also published more than 30 papers in International Conference proceedings. He was a CoPrincipal Investigator for a funded project of Tamilnadu State Council for Science and Technology. Currently, he is working as a Professor in the Department of Mechanical Engineering, Kalasalingam Academy of Research and Education since, 2004.

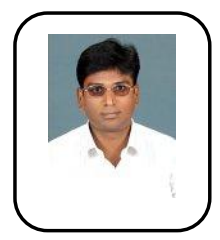

Dr. S. Rajesh obtained his Bachelor's degree in Mechanical Engineering from Alagappa Chettiar College of Engineering and Technology; Karaikudi affiliated to Madurai Kamaraj University (2002) and completed his Master's degree in Computer Aided Design from the Alagappa Chettiar College of Engineering and Technology, Karaikudi affiliated to Anna University Chennai (2008). Then he was awarded his $\mathrm{PhD}$ in Mechanical Engineering from Kalasalingam Academy of Research and Education, Krishnankoil in 2014. He published more than 10 papers in the reputed journals and also published more than 17 international conference papers. Presently, he is working as an Associate Professor \& Head of Department of Mechanical Engineering, Kalasalingam Academy of Research and Education with more than 15 years of teaching expertise.

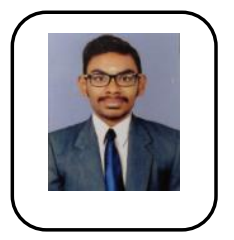

G.M. Mukesh Vaidya, UG Student, Mechanical Engineering Department, Kalasalingam Academy of Research and Education, krishnankoil, Tamilnadu, India. $\mathrm{He}$ is member of "IUCEE-SCALE" students council and working under more than 20 projects and research works and also have Industrial Experiences in Part Time during his period of Study. Having some membership in SAE, ISTE. He also Published 2 International Journals and 2 International and 3 National Publications. His Community Service Project was awarded by ISTE Students Chapter and IUCEE - Scale Students Council. 